\title{
A importância da correta dosagem de aditivo controlador de hidratação: Estudo de caso de manifestações patológicas em uma bacia de contenção
}

\author{
C. A. M. H. da Luz ${ }^{1 *}$, F. M. Pereira ${ }^{2}$ \\ *Autor de contato: claudiaaiala@rede.ulbra.com.br \\ ${ }^{1}$ Curso de Engenharia Civil, Universidade Luterana do Brasil, Canoas, Brasil \\ ${ }^{2}$ Curso de Engenharia Civil, Universidade Luterana do Brasil, Canoas, Brasil
}

\begin{abstract}
RESUMO
Os aditivos estão sendo cada vez mais utilizados na indústria da construção, porém deve-se ter cautela no seu emprego, visto que o uso incorreto pode acarretar manifestações patológicas nas estruturas de concreto armado. O presente trabalho tem como objetivo investigar a ocorrência de manchas no concreto e o atraso para atingir a resistência esperada em uma peça de concreto armado. É apresentado um estudo de caso, onde foram analisadas manifestações patológicas de uma parede de concreto, em bacia de contenção de obra no município de Rio Grande, no Rio Grande do Sul, apontando suas possíveis causas e considerações de ações que teriam evitado tais manifestações patológicas. Os resultados obtidos através do estudo de caso indicaram como possíveis causas a dosagem excessiva de aditivo controlador de hidratação, uma mistura ineficiente do concreto, aliado à execução de uma cura não adequada. Considerou-se que há a necessidade de um acompanhamento técnico durante a concretagem e um controle mais rigoroso no processo de dosagem de aditivos, visto que estes influenciam na resistência à compressão e propriedades do concreto, bem como na estética da peça, podendo alterar sua aparência.
\end{abstract}

Palavras-chave: Concreto; aditivo controlador de hidratação; manchamento; retardo de pega; resistência à compressão.

Citar como: Luz, C. A. M. H. da, Pereira, F. M. (2021), "A importância da correta dosagem de aditivo controlador de hidratação: Estudo de caso de uma bacia de contenção", CONPAT 2021.

${ }^{1}$ Graduanda em engenharia civil, Universidade Luterana do Brasil, Canoas, Brasil.

${ }^{2}$ Curso de Engenharia Civil, Universidade Luterana do Brasil, Canoas, Brasil.

Contribuição de cada autor

Neste trabalho o autor C. A. M. H. da Luz foi responsável pela execução do trabalho sob orientação da professora F. M. Pereira.

The Importance of Correct Dosage of Hydration Control Additive: Case Study of Pathological Manifestations in a Containment Area

\section{ABSTRACT}


Admixtures are being used more and more in the building industry, but caution should be exercised in their use, since incorrect use can lead to pathological manifestations in reinforced concrete structures. This work aims to investigate the occurrence of stains in concrete and the delay to reach the expected strength in a reinforced concrete structure. A case study is presented, where pathological manifestations of a concrete wall were analyzed in a work containment basin in the city of Rio Grande, in Rio Grande do Sul, pointing out its possible causes and considerations of actions that would have avoided such pathological manifestations. The results obtained through the case study indicated as possible causes the excessive dosage of the hydration controller admixture, an inefficient concrete mixture, together with the execution of an inadequate cure. It was considered that there is a need for technical monitoring during concreting and a more rigorous control in the additive dosing process, as they influence the compressive strength and properties of the concrete, as well as the aesthetics of the piece, and may change its appearance.

Keywords: Concrete; hydration controller admixture; staining; setting time delay; compressive strength.

\section{La importancia de la dosificación correcta del aditivo controlador de hidratación: estudio de caso de manifestaciones patológicas en un área de contención}

\section{RESUMEN}

Los aditivos se utilizan cada vez más en la industria de la construcción, pero se debe tener precaución en su uso, ya que un uso incorrecto puede provocar manifestaciones patológicas en las estructuras de hormigón armado. El presente trabajo tiene como objetivo investigar la aparición de manchas en el hormigón y el retraso para alcanzar la resistencia esperada en una pieza de hormigón armado. Se presenta un estudio de caso, donde se analizaron manifestaciones patológicas de un muro de hormigón en una cuenca de contención de obra en el municipio de Rio Grande, en Rio Grande do Sul, señalando sus posibles causas y consideraciones de acciones que habrían evitado tales manifestaciones patológicas. Los resultados obtenidos a través del caso de estudio señalan como posible la dosificación excesiva del aditivo controlador de hidratación, una mezcla de concreto ineficiente, junto con la ejecución de un curado inadecuado. Se consideró que existe la necesidad de un seguimiento técnico durante el hormigonado y un control más riguroso en el proceso de dosificación de los aditivos, ya que influyen en la resistencia a la compresión y las propiedades del hormigón, así como en la estética de la pieza, pudiendo cambiar su aspecto.

Palabras llave: Concreto; aditivo controlador de hidratación; retardo del tiempo de fraguado; resistencia a la compresión.

\section{INTRODUÇÃO}


A construção civil adere ao uso de aditivos para melhorar o desempenho e a qualidade dos concretos, além de um aumento na economia. Conforme Neville (2016), o emprego de aditivos proporciona o uso de concreto em situações não favoráveis, onde seria difícil ou até impossível viabilizar a utilização de concreto sem aditivos. Os aditivos têm o objetivo de modificar as propriedades do concreto, a fim de controlar a hidratação, melhorar a trabalhabilidade, retardar a pega, acelerar a pega, incorporar ar, impermeabilização, entre outros.

$\mathrm{O}$ aditivo controlador de hidratação atua diretamente nas reações de hidratação do cimento, controlando assim o processo de início de cristalização e, em decorrência, acaba possibilitando controlar a pega do cimento. É utilizado em casos em que o concreto será transportado da central dosadora, locais em que é necessário percorrer longas distâncias, evitando assim a perda do concreto por vencimento, ou também em casos de temperatura ambiente elevada ou reaproveitamento do concreto em centrais dosadoras. Os aditivos são excelentes aliados quando utilizados em dosagens corretas e para seu fim específico, porém se utilizados de forma incorreta, com dosagens em excesso ou em quantidades menores do que deveriam, não proporcionam o resultado esperado, podendo causar problemas no concreto ainda fresco ou após a desforma. $\mathrm{O}$ correto emprego dos aditivos prevê o uso de dosadores calibrados e a execução/aplicação feita por pessoal capacitado, a fim de evitar possíveis superdosagens ou dosagens insuficientes.

Em meados do ano de 2017 foi construída uma bacia de contenção na sede de uma empresa de fertilizantes localizada na cidade de Rio Grande, no Rio Grande do Sul. De acordo com a NBR 17505 (2013), uma bacia de contenção “é uma área constituída por uma depressão, pela topografia do terreno ou, ainda, limitada por diques, destinada a conter eventuais vazamentos de produtos." Deve ser dimensionada de acordo com o volume do produto ou dos produtos armazenados em tanques, e funciona como uma barreira, evitando que o líquido contamine o meio ambiente, ou até mesmo a contaminação de colaboradores que trabalhem no local. Segundo a mesma norma, "todos os tanques que armazenem líquidos devem ser dotados de meios que impeçam que a ocorrência acidental de derramamento de líquidos venha a colocar em risco instalações importantes ou propriedades adjacentes, ou alcancem cursos d'água." A construção da bacia de contenção é de extrema importância, não somente do ponto de vista ambiental, mas também econômico. Trabalhar prevenindo uma contaminação é economicamente mais viável do que acabar tendo-se um passivo que pode ocorrer em notificação de órgão ambiental e, consequentemente, multa ou bloqueio de operações até a solução do problema.

A construção desta bacia de contenção contou com aproximadamente 30 colaboradores, entre pedreiros, carpinteiros e armadores, um engenheiro residente e um técnico em segurança. Durante a obra da bacia de contenção foi consumido aproximadamente $1.700 \mathrm{~m}^{3}$ de concreto usinado, em uma área superior à $2.000 \mathrm{~m}^{2}$. A obra se deu em etapas, em cada etapa eram montadas armaduras, formas e em seguida a concretagem das paredes da bacia de contenção. Logo após a desforma de uma parede já era montada a parede seguinte. De todos os caminhões de concreto foram moldados corpos de prova, a fim de se manter uma rastreabilidade e controle do concreto, bem como o controle de qualidade em cada etapa de concretagem.

Em uma das paredes da bacia de contenção foram encontradas manifestações patológicas logo após a desforma do concreto.

Diante disso, o presente trabalho tem por objetivo investigar e apontar as possíveis causas das manifestações patológicas observadas em paredes da bacia de contenção, através de um estudo de caso, com uso de imagens e resultados de ensaios apresentados em relatórios técnicos. Pretendese, ainda, apresentar possíveis medidas e procedimentos que evitariam a ocorrência de tais manifestações patológicas.

\section{ADITIVO CONTROLADOR DE HIDRATAÇÃO}


Como próprio nome se refere o aditivo controlador de hidratação $(\mathrm{CH})$ tem como função principal controlar a hidratação do cimento Portland. Também é conhecido comercialmente como inibidor ou estabilizador de hidratação. Os aditivos controladores de hidratação podem ser considerados também um tipo de retardador de pega, pois acabam influenciando o tempo de início de pega quando se tem o seu uso no concreto.

Os aditivos retardadores têm ação diferente dos controladores de hidratação. De acordo com Neville (2016) há a possibilidade de que alterem o crescimento ou a morfologia dos cristais sendo absorvidos por uma película de cimento hidratado que foi formada muito rápido. Logo eles retardam o crescimento dos núcleos de hidróxido de cálcio, tornando-se uma barreira evitando assim a continuação da hidratação. Estudos calorimétricos realizados por Paolini e Khurana (1998) evidenciaram que os retardadores de pega convencionais exercem uma influência maior sobre as fases silicato do que sobre a hidratação do $\mathrm{C}_{3} \mathrm{~A}$. Portanto estes compostos afetam mais o desenvolvimento da resistência inicial, do que a alteração da reologia inicial do concreto fresco.

Em contrapartida, o aditivo controlador de hidratação é capaz de baixar a concentração de sulfato de cálcio na solução e retardar a reação de todos os minerais do clínquer. O controlador de hidratação é um agente tensoativo de superfície designado para inibir a nucleação na superfície de hidratos ricos em íons de cálcio. Desta forma, o mecanismo de ação fundamenta-se na inibição da nucleação do C-S-H (silicato hidratado de cálcio) e $\mathrm{CH}$ (hidróxido de cálcio). Quando o aditivo controlador de hidratação é adicionado, durante ou após o período de indução, diminui a nucleação e crescimento do C-S-H e CH. Quando os núcleos já estão formados, o controlador, além de retardar o crescimento dos hidratos, altera a morfologia externa dos hidratos subsequentemente formados. Os controladores de hidratação são capazes de interromper a formação dos hidratos de $\mathrm{CSH}$ primário e desacelerar o $\mathrm{C}_{3} \mathrm{~A}$, o que indica que em cimento Portland esse tipo de aditivo evita o rápido crescimento de $\mathrm{CSH}$ primário, a partir do $\mathrm{C}_{3} \mathrm{~S}$, e diminui a precipitação dos hidratos do $\mathrm{C}_{3} \mathrm{~A}$ (PAOLINE e KHURANA, 1998).

A American Society for Testing and Materials indica que concretos preparados na temperatura de $10^{\circ} \mathrm{C}$ possuem início de pega três horas mais demorado e final de pega nove horas superior que os mesmos concretos se preparados a $23^{\circ} \mathrm{C}$, logo a temperatura também influencia na interação do aditivo controlador de hidratação com o cimento (ASTM C 403, 1992).

Conforme SOUZA (2007), na prática o aditivo controlador de hidratação tem a capacidade de retardar o crescimento de núcleos já formados, causando a possibilidade do material ser estabilizado algumas horas depois de misturado, desde que antes do início de pega. $\mathrm{O}$ curso da hidratação é retomado quando um aditivo ativador é inserido à mistura, ou quando o estabilizador for consumido por completo, sendo assim o processo de hidratação recomeça regularmente com o endurecimento.

O uso do aditivo controlador de hidratação possibilita um controle mais previsível do retardo de pega dos concretos, principalmente em dias quentes, sem prejudicar propriedades futuras devido a adição de água para recuperar a perda excessiva de abatimento ou atraso de pega. É amplamente utilizado quando a concretagem a ser realizada está localizada a longas distâncias da central dosadora (BENINI, 2005).

O início da pega do concreto com controlador de hidratação vai depender da dosagem de aditivo, quanto maior for, mais tempo irá levar para se ter o início da pega e consequentemente o fim de pega também irá levar mais tempo. Acabado o efeito do aditivo, o concreto tem seu caminho natural de hidratação do cimento.

É importante a dosagem correta do aditivo, para que não se tenha problemas futuros com o concreto. No caso de superdosagem pode impactar em retardo de pega ou em pega diferenciada em pontos diferentes da peça de concreto, caso a mistura tenha sido deficiente. Por isso a cura adequada é tão importante. Se houver superdosagem e a cura ineficiente o concreto pode ter problemas no endurecimento resultando em baixa resistência. 
A cura do concreto é um procedimento muito importante para que se tenha um resultado satisfatório de endurecimento da peça de concreto, atendendo os requisitos de resistência exigidos no projeto, e evitando o surgimento de fissuras e trincas na estrutura. De acordo com a NBR 14931 (2004) a cura tem a finalidade de evitar a perda de água pela superfície exposta, assegurar uma superfície com resistência adequada, e assegurar a formação de uma capa superficial durável. Elementos estruturais devem ser curados até que obtenham uma resistência à compressão igual ou maior que $15 \mathrm{MPa}$.

Com isso, o procedimento de cura quando há o uso de aditivo controlador de hidratação deve ser realizado com cuidado especial, visto que o aditivo retardou o processo de hidratação natural do cimento. É importante este cuidado a fim de que não se tenha uma cura ineficiente ou durante tempo insuficiente.

\section{ESTUDO DE CASO}

O trabalho proposto trata de um estudo de caso a respeito da ocorrência de manifestações patológicas em uma parede de concreto de uma bacia de contenção.

A investigação foi feita através de inspeção visual, registro fotográfico da manifestação patológica, coleta de dados do concreto usado, coleta de informações diversas, entrevistas com engenheiros responsáveis e mestre de obras, e análise de dados dos ensaios de resistência à compressão e esclerometria.

A figura 1 ilustra as etapas da realização do trabalho.

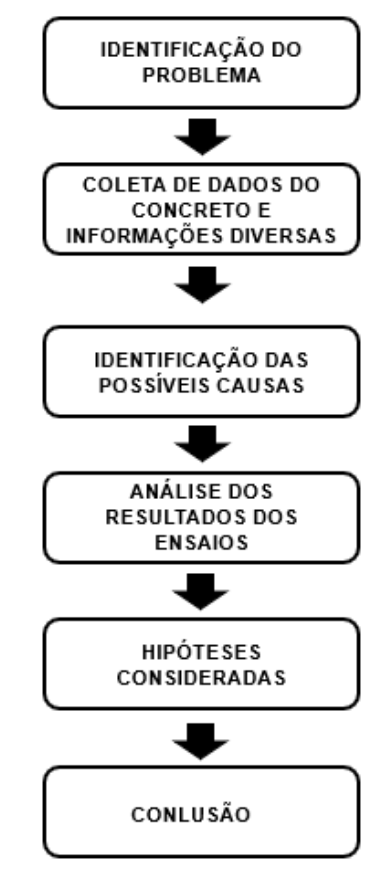

Figura 1. Fluxograma: etapas do trabalho.

\subsection{Caracterização da bacia de contenção}

A construção da bacia de contenção para área de tancagem da empresa contava com área total de $2.894 \mathrm{~m}^{2}$, na cidade de Rio Grande, Rio Grande do Sul. Foram utilizados $1.700 \mathrm{~m}^{3}$ de concreto durante toda a obra e a resistência à compressão exigida em projeto (fck) era de $40 \mathrm{MPa}$. $\mathrm{O}$ concreto foi fornecido por empresa com sede na cidade de Pelotas, distante $56 \mathrm{~km}$ de Rio Grande, o que determinou o emprego de aditivo controlador de hidratação à mistura, a fim de garantir que 
o percurso fosse feito com segurança em relação ao prazo de vencimento do concreto. A figura 2 apresenta o croqui de todo o perímetro da bacia de contenção.

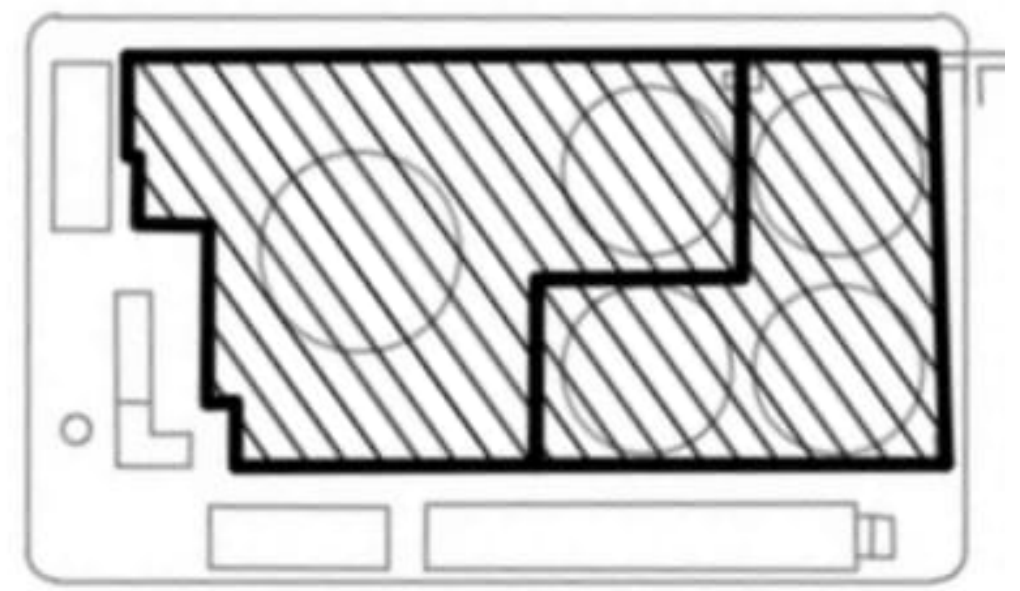

Figura 2. Croqui do perímetro da bacia de contenção.

Em uma das paredes da bacia de contenção foram encontradas manifestações patológicas logo após a desforma do concreto. A localização das manifestações patológicas pode ser vista na figura 3.

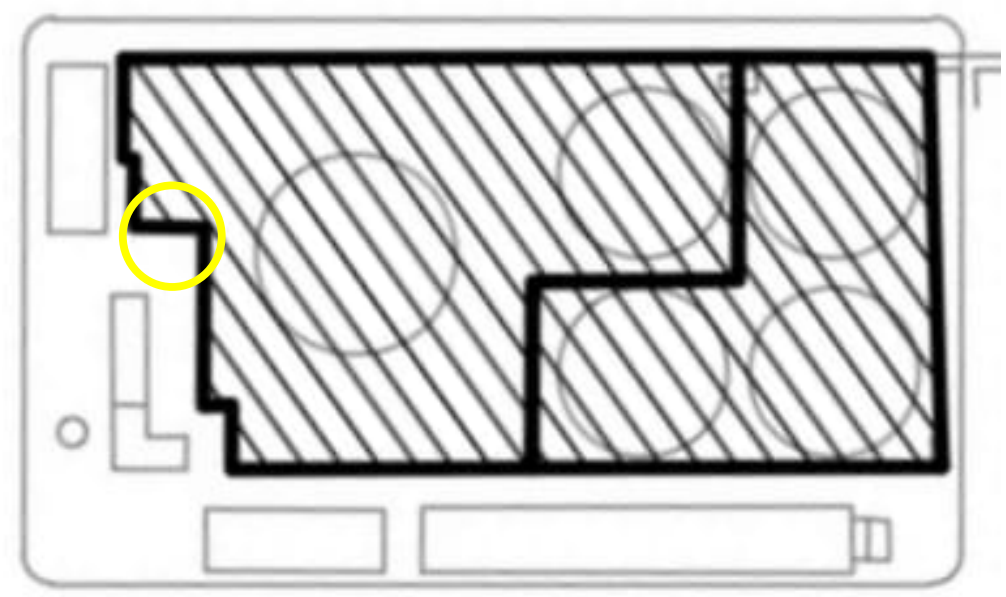

Figura 3. Localização das manifestações patológicas.

\subsection{Etapas da construção}

No início da construção foi avaliada a instalação de uma central de concreto na obra ou próximo, em função do volume que seria usado, porém, por razões econômicas e por falta de espaço, a ideia de uma central local não evoluiu. Então, em todas as concretagens houve a necessidade do concreto ser transportado de uma cidade à outra, cerca de $56 \mathrm{~km}$ distante da obra, visto ter sido feita a opção por concreteira da cidade de Pelotas.

A obra foi executada em etapas, e cada parede tinha uma identificação e medidas específicas, especificadas no projeto, conforme mostra a figura 4. 


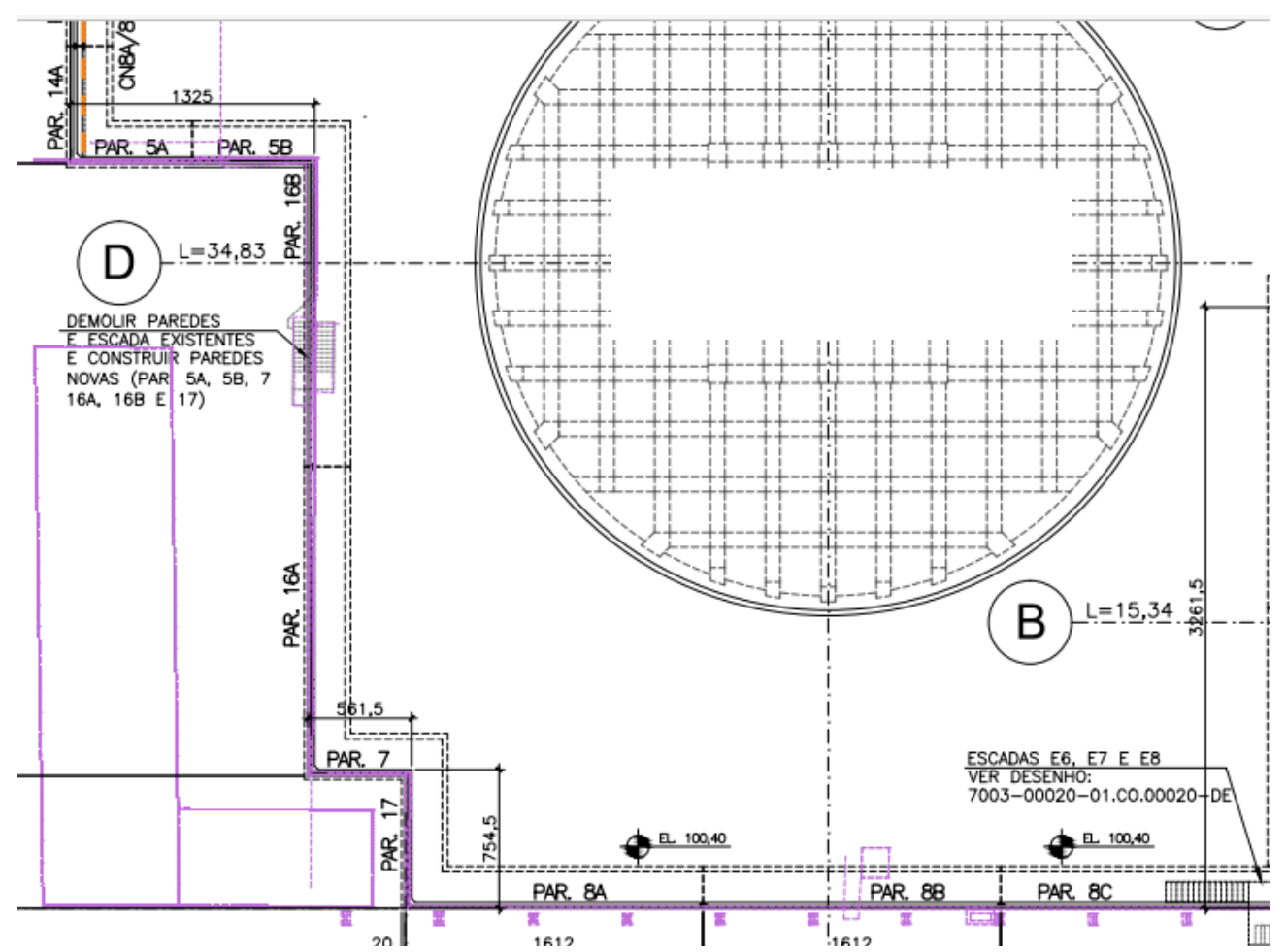

Figura 4. Identificação de paredes da bacia de contenção, próximas ao tanque de ácido.

Primeiramente eram montadas as armaduras, logo após eram montadas as formas, que já vinham em módulos específicos paras as medidas das paredes, e então era realizada a concretagem.

No recebimento do aço, era realizado um check-list de verificação, avaliando se não apresentava ferrugem, sujeira e se estava de acordo com o pedido. Logo após a verificação, o aço era armazenado em local próximo à obra e distante do chão, sempre que possível em local coberto. As barras de aço já eram entregues dobradas pelo fornecedor, e no local da obra as peças eram montadas de acordo com a parede a ser executada, conforme estabelecido no projeto.

Logo após a etapa de montagem de armaduras estar concluída, eram então montadas as formas de madeira. As formas eram com painéis de madeira e perfil em aço, sendo que antes da montagem era aplicado desmoldante. Montavam-se as formas e então era realizado um check-list de verificação sob responsabilidade do engenheiro residente. Nesse check list avaliava-se a prumada, a aplicação do desmoldante, os escoramentos e se estavam de acordo com o que o projeto indicava.

Com base no cronograma e no avanço da obra, foram programadas as datas de concretagem.

Como o concreto percorria longa distância até a obra, para evitar o início de pega antes da chegada à obra e descarga, foi utilizado aditivo controlador de hidratação em todas as unidades de produto utilizadas nas concretagens. Quando o concreto chegava à obra, era realizado um check-list de verificação, onde se fazia o ensaio de abatimento do tronco de cone e a moldagem de exemplares para ensaio à compressão nas idades de 7, 28 e 63 dias.

$\mathrm{O}$ ensaio de abatimento do concreto, também conhecido como slump test, é parte do controle e recebimento do concreto (ABNT NBR 12655, 2015), através da consistência medida é possível avaliar a trabalhabilidade do concreto e assim verificar se está de acordo com as especificações da solicitação. O ensaio era realizado logo que o concreto chegava à obra, segundo as recomendações da NBR NM 67 (ABNT, 1998), em vigor na época da concretagem. Se o slump estivesse dentro dos parâmetros solicitados pelo projeto, o concreto então era recebido e lançado. O concreto era lançado muitas vezes com apoio de bomba estacionária, e os colaboradores faziam a vibração do concreto, a fim de não deixar pontos vazios e manter a uniformidade da peça. 
Para o controle e aceitação do concreto, de cada caminhão eram moldados seis corpos de prova, segundo a NBR 5738 (ABNT, 2018). Após a desmoldagem os corpos de prova eram submetidos a cura úmida, sendo posteriormente levados para laboratório para o ensaio de resistência à compressão, realizado aos 7, 28 e 63 dias de idade.

A desforma do concreto das paredes da bacia ocorria após quatro dias da concretagem.

\subsection{Descrição dos danos observados}

Logo após a desforma do concreto, na parede 5A foram encontradas diversas manifestações patológicas. A Figura 5 mostra os principais danos observados.

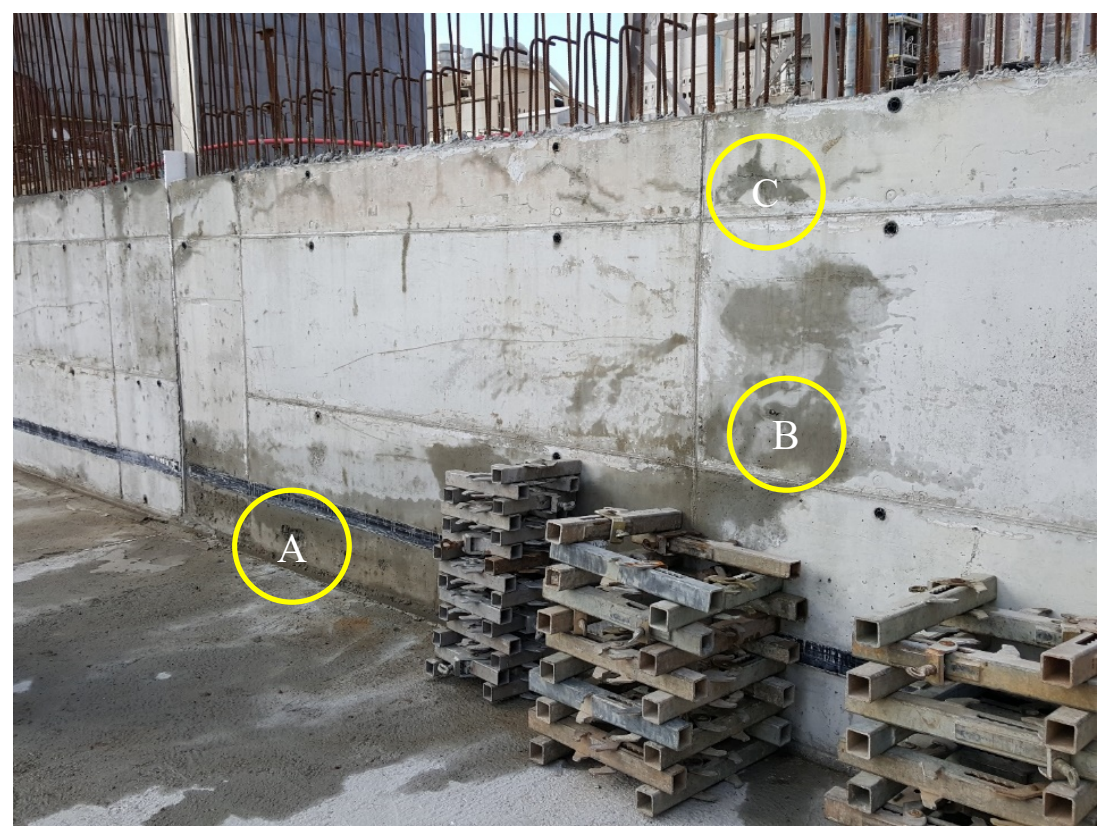

Figura 5. Parede 5A.

As manifestações patológicas encontradas foram 1) desplacamento superficial do concreto no momento da desforma, indicando que o concreto não teria atingido o fim de pega, conforme mostra a figura 6 (ponto A na figura 5); 2) manchamentos e falha na concretagem (ponto B na figura 5) e 3) fissuras (ponto $\mathrm{C}$ na figura 5).

A figura 7 mostra parte do manchamento observado na parede, bem como falha de concretagem.

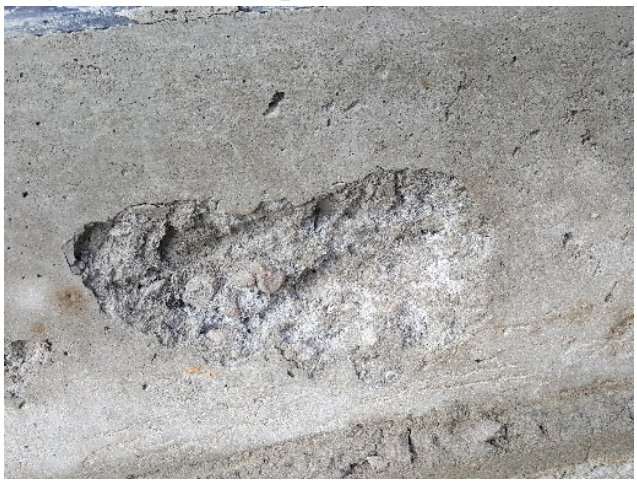

Figura 6. Desplacamento do concreto.

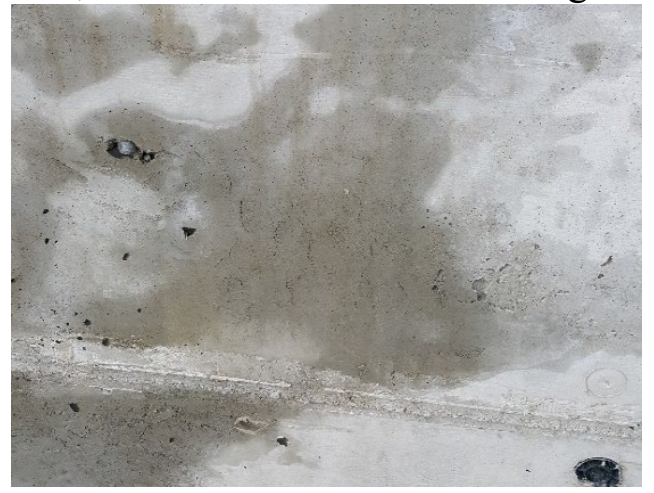

Figura 7. Manchamento observado na parede e falha de concretagem. 
O manchamento observado caracteriza-se pela presença de manchas mais escuras, com aspecto de umidade, conforme mostra a figura 7. As manchas se mantiveram na peça por aproximadamente dois meses, e podem ser um indicativo de pega diferencial no concreto. A imagem apresentada na figura 7 também mostra falha de concretagem, com agregados aparentes, possivelmente decorrente de vibração mal executada, resultando em ninho de concretagem.

A figura 8 apresenta as fissuras identificadas na parede $5 \mathrm{~A}$, possivelmente decorrente de retração plástica, o que evidencia a diferença do tempo de pega do concreto em pontos distintos da parede.

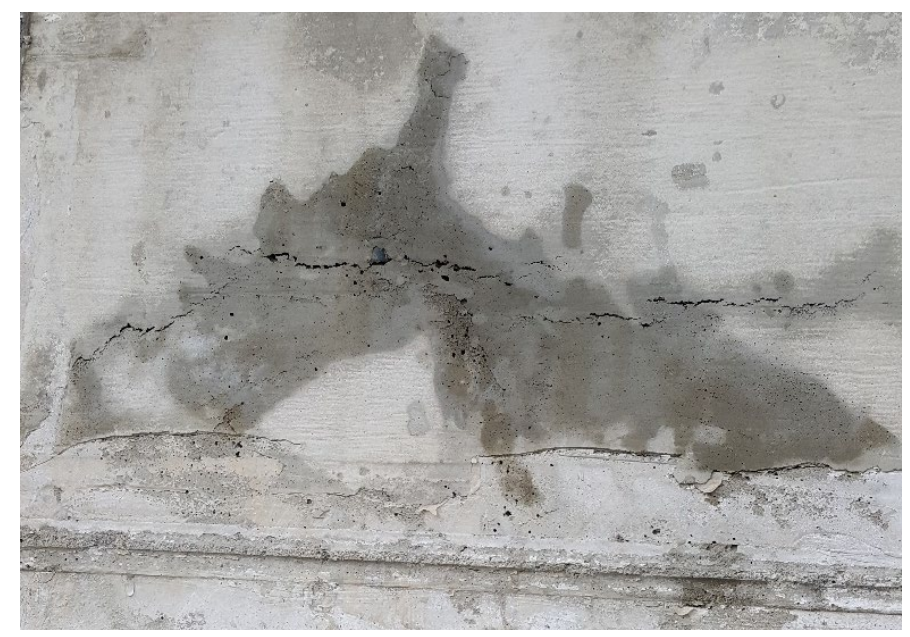

Figura 8. Concreto apresentando retração.

Durante a obra foi efetuado o controle da resistência do concreto através de amostragem total das concretagens, seguindo-se as recomendações da NBR 12655 (ABNT, 2015). Os corpos de prova moldados foram rompidos com 7 dias, 28 dias e 63 dias.

A Tabela 1 mostra os resultados de resistência à compressão nas idades de 7 e 28 dias, referente ao concreto lançado para a concretagem da parede $5 \mathrm{~A}$.

Tabela 1. resultados dos rompimentos de corpos de prova aos 7 e 28 dias.

\begin{tabular}{|c|c|c|c|c|c|c|}
\hline Caminhão & $\begin{array}{c}\text { Volume } \\
\left(\mathrm{m}^{3}\right)\end{array}$ & Moldagem & Idade & $\begin{array}{c}\text { Tensão } \\
\text { (MPa) }\end{array}$ & Idade & $\begin{array}{l}\text { Tensão } \\
\text { (MPa) }\end{array}$ \\
\hline \multirow{2}{*}{ IRN 0312} & \multirow{2}{*}{3} & \multirow{2}{*}{$18 / 01 / 2018$} & \multirow{2}{*}{7} & 25,01 & \multirow{2}{*}{28} & 34,35 \\
\hline & & & & 25,4 & & 38,06 \\
\hline
\end{tabular}

Fonte: Empresa construtora (2017).

Na maioria das unidades de produto utilizadas na concretagem das paredes da bacia o concreto atingiu a resistência esperada com 28 dias. Porém, para a carga de concreto utilizado para a moldagem da parede $5 \mathrm{~A}$, o resultado foi diferente, abaixo do fck de projeto, conforme pode ser constatado na Tabela 1.

Aos 28 dias o concreto ainda não havia atingido a resistência esperada, denotando um atraso para atingir a resistência de projeto.

Com o passar dos dias, após a concretagem da parede 5A, as manchas se mantiveram evidentes. Foi sugerido, então, a realizar uma análise in loco para verificar a qualidade do concreto, visto ser de suma importância que a peça estivesse dentro dos parâmetros exigidos pelo projeto, pois em caso de vazamento de um dos tanques essa bacia deve conter o líquido, a fim de evitar danos ao 
meio ambiente. Um ensaio não destrutivo foi então realizado, sobre a superfície manchada, com o intuito de verificar a qualidade do concreto em pontos que continham as manifestações patológicas. $\mathrm{O}$ ensaio foi realizado com uso de um aparelho de esclerometria, o esclerômetro, que tem por finalidade medir a dureza superficial, possibilita verificar a uniformidade do concreto em diferentes partes da estrutura. Não sendo possível a extração de testemunho, inicialmente o ensaio de esclerometria foi requisitado com a intenção de investigar a resistência, o que não é adequado. Observa-se que é um ensaio preliminar na avaliação, e deve ser usado como uma primeira análise de qualidade do concreto. Os resultados obtidos estão apresentados na tabela 2.

Tabela 2: Resultados do ensaio de esclerometria.

\begin{tabular}{|c|c|c|c|c|}
\hline \multicolumn{5}{|c|}{ Resultados da Esclerometria } \\
\hline & Ponto 1 & Ponto 2 & Ponto 3 & Ponto 4 \\
\hline $\begin{array}{c}\text { Índice } \\
\text { Esclerométrico }\end{array}$ & 39,2 & 38,4 & 39,5 & 39,2 \\
\hline
\end{tabular}

Fonte: Empresa construtora (2017).

A resistência à compressão exigida pelo projeto (fck), 40MPa aos 28 dias, só foi atingida com 63 dias, conforme indica tabela 3.

Tabela 3. Resultados rompimentos corpos de prova com 63 dias.

\begin{tabular}{|c|c|c|}
\hline Idade & Tensão (Mpa) & Elemento Concretado \\
\hline \multirow{2}{*}{63} & $\mathbf{4 5 , 0 8}$ & \multirow{2}{*}{ Parede $5 \mathrm{~A}$} \\
\cline { 2 - 3 } & 39,26 & \\
\hline
\end{tabular}

Fonte: Empresa construtora (2017).

\section{HIPÓTESES CONSIDERADAS}

Fazendo-se uma análise global dos danos apresentados, e considerando-se os resultados dos ensaios realizados pela empresa, é possível considerar que provavelmente houve uma superdosagem de aditivo controlador de hidratação, o que determinou a ocorrência de retardo de pega, determinando tempos de pega diferentes no concreto e consequente manchamento.

De acordo com estudos realizados por Antoniazzi et al. (2020), para pastas aditivadas com aditivo estabilizador de hidratação, o tempo de início de pega foi superior a 48h. Quando utilizado em teores moderados, elevou a resistência à tração, já quando usado em altos teores, diminuiu tanto a resistência à tração quanto à compressão, indicando possível retardo na formação dos compostos hidratados.

Dias et al. (2010) verificaram que concretos com dosagem normal de aditivo retardador de pega registraram maior resistência à compressão com 28 dias, no entanto há um significativo atraso no ganho de resistência em concretos que foram dosados com seis vezes a dosagem normal. $\mathrm{O}$ concreto com a dosagem seis vezes mais do que a dosagem normal, atingiu uma resistência similar a do concreto com dosagem normal, porém só com 119 dias. Mesmo atingido a resistência de forma tardia, não deve ser uma abertura para que produtores de concreto negligenciem o controle de qualidade.

Visto que os danos observados foram em uma carga fornecida com volume de $3 \mathrm{~m}^{3}$, e a grande maioria das demais cargas eram com volume de $8 \mathrm{ou} 10 \mathrm{~m}^{3}$, uma hipótese a ser considerada é que 
a quantidade do aditivo tenha sido dosada para uma quantidade maior de concreto, sem considerar o menor volume do carregamento, de apenas $3 \mathrm{~m}^{3}$.

A diferença de coloração observada no concreto evidencia uma pega diferenciada em vários pontos da parede concretada, podendo ter sido causada por um concreto que não foi corretamente misturado, apresentando apenas em alguns pontos as machas decorrentes de tempo de pega diferenciado.

Casali et al. (2020) observou após ensaios com argamassas aditivadas com estabilizador de hidratação que essas argamassas retêm mais água, sendo essa retenção influenciada pelo uso do aditivo estabilizador de hidratação.

O concreto, aparentemente, estava ainda em processo de "enrijecimento" quando desformado. A desforma ocorria sempre quatro dias após a concretagem, o que pode ter causado o desplacamento observado na superfície.

As fissuras representam um fenômeno de retração, possivelmente causado pelo retardo de pega decorrente de um excesso de aditivo, visto que o concreto permaneceu por mais tempo "fresco", perdendo água para o ambiente. Já a falha de concretagem observada revela um concreto que não foi vibrado o suficiente, o que determinou o surgimento de tal manifestação patológica.

\section{CONCLUSÃO OU CONSIDERAÇÕES FINAIS}

A importância do controle de processos na obra se torna cada dia mais importante, controlar todas as etapas desde a produção do concreto até a aplicação na obra. O controle tecnológico do concreto é de suma importância, para que se tenha rastreabilidade caso venha a surgir algum problema ou até mesmo para evidenciar que as exigências de projeto foram atendidas.

Como observado, o aditivo pode ajudar muito nas concretagens se dosado corretamente, porém em caso de superdosagem torna-se prejudicial, retardando excessivamente a pega do concreto, ou até mesmo promovendo sua inutilização, ocasionando atrasos à obra e prejuízos econômicos.

Nesse estudo de caso possivelmente a causa das manifestações patológicas foram a superdosagem do aditivo controlador de hidratação que acarretou um retardo de pega excessivo, determinando desplacamento do concreto na desmoldagem, manchas escurecidas na superfície e fissuras.

O caso estudado reforça a importância da utilização de equipamentos adequados, com equipe treinada para essa atividade, não dispensando de forma alguma a etapa de cura do concreto.

No presente caso, se o aditivo tivesse sido dosado corretamente, ele faria a sua atuação como deve ser, controlando a hidratação em função da distância que o concreto percorreu, a fim de não entrar em pega antes do lançamento. Igualmente, evitaria a ocorrência de manifestações patológicas como as observadas na parede: manchas, diferença de coloração, retração e desplacamento do concreto.

Sempre que se fizer necessário o uso de aditivos controladores de hidratação é recomendado que se faça uma cura úmida adequada e com tempo prolongado. É importante o concreto ser vibrado suficientemente, para que não se tenha ninhos de concretagem. E que o controle tecnológico do concreto seja realizado corretamente, com uma rastreabilidade eficiente e os corpos de prova enviados para laboratórios qualificados.

Sempre que houver problemas onde se tenha dúvida da resistência do concreto é importante fazer a extração de testemunhos. O uso de métodos não destrutivos sempre é válido para identificar possíveis diferenças de homogeneidades, porém somente com a extração de testemunhos possibilitará a verificação da resistência atingida pelo concreto. Nesse caso foi utilizado o ensaio de esclerometria. Conforme Neville e Brooks (2013), o ensaio com esclerômetro é válido como 
uma medida de uniformidade e qualidade relativa do concreto em uma estrutura ou da produção de elementos similares pré-moldados, mas não como um critério de aceitação. 


\section{REFERÊNCIAS}

Associação Brasileira de Normas Técnicas. (2013). NBR 17505: Armazenamento de líquidos inflamáveis e combustíveis. Rio de Janeiro.

Associação Brasileira de Normas Técnicas. (1998). NBR NM 67: Concreto - Determinação da Consistência pelo Abatimento do Tronco de Cone. Rio de Janeiro.

Associação Brasileira de Normas Técnicas. (2018). NBR 5738: Concreto - Procedimento para Moldagem e Cura de Corpos-de-Prova. Rio de Janeiro.

Associação Brasileira de Normas Técnicas. (2015). NBR 12655: Concreto - Concreto de Cimento Portland - Preparo, Controle e Recebimento. Rio de Janeiro.

Associação Brasileira de Normas Técnicas. (2004). NBR 14931: Concreto - Procedimento execução de estruturas em concreto. Rio de Janeiro.

ASTM International (1992) ASTM C 403: Standart Test Method for Time of Setting of Concrete Mixtures by Penetration Resistance. Philadelphia.

Antoniazzi, J. P. et al.(2020) Ação dos aditivos estabilizador de hidratação e incorporador de ar em pastas de cimento Portland. Ambiente Construído, [s. l.], v. 20, n. 3, p. 249-262. Disponível em: https://doi.org/10.1590/s1678-86212020000300427

Benini, H. (2005), "Reaproveitamento de concreto fresco dosado em central com o uso de AEH". Tese de Mestrado, Universidade de São Paulo. São Paulo.

Casali, J. M. et al. (2020), Propriedades mecânicas das argamassas estabilizadas: evolução com a idade e o grau de hidratação. Ambiente Construído, [s. l.], v. 20, n. 3, p. 263-283. Disponível em: https://doi.org/10.1590/s1678-86212020000300428

Neville, A.M.; Brooks, J.J. (2013), “Tecnologia no concreto". 2 ed. Porto Alegre, Brasil.

Neville, A. M., Brooks, J.J. (2016), "Propriedades do concreto". 5.ed. Porto Alegre, Brasil.

Paolini, M. \& Khurana, R.,(1998) Admixtures for Recycling of Waste Concrete. Cement and Concrete Composites, 20, p. 221-229, 1998.

Souza, A. F. de et. al. (2007), "Otimização do uso de aditivo estabilizador de hidratação do cimento em água de lavagem dos caminhões-betoneira para produção de concreto". Tese de Mestrado, Universidade Federal de Santa Catarina, Santa Catarina. 